\title{
Media Coverage of Summer Paralympic Games (1992-2008): A Case Study of the Czech Republic
}

\author{
Alice N. Tejkalová \\ Head of the Institute of Communication Studies and Journalism, Faculty of Social Sciences, \\ Charles University in Prague Smetanovo nábř. 6, 11001 Prague, Czech Republic \\ Email: alice.tejkalova@fsv.cuni.cz
}

\section{Wadim Strielkowski}

\begin{abstract}
Department of Marketing Communication and PR, Institute of Communication Studies and Journalism, Faculty of Social Sciences, Charles University in Prague, Smetanovo nábř. 6, 11001 Praha 1, Prague, Czech Republic Email: strielkowski@fsv.cuni.cz
\end{abstract}

\section{Doi:10.5901/mjss.2015.v6n2p578}

\section{Abstract}

Our paper aims at analyzing the Czech media coverage of Summer Paralympic Games (1992-2008) based on the qualitative analysis and the estimation of type and length of articles in four Czech major newspapers. We employ the comparative content analysis of the articles from the daily newspapers two weeks prior and one month after the respective event using the article total space ranging from very short to very long. Our results demonstrate that the news coverage Summer Paralympic Games and athletes with disabilities in the Czech media sharply declined in case of the 2008 Beijing Summer Paralympic Games. These findings might be attributed to the orientation of Czech sport media on "mainstream" (and therefore more profitable) sport events (e.g. football and ice hockey), as well as some endogenous issues in the Czech Paralympic movement.

Keywords: mass media, athletes with disabilities, Summer Paralympic Games, Czech Republic

\section{Introduction}

The participation of athletes with disabilities in collective sport events broadcasted or covered by the mainstream mass media has dramatically increased over the past decades (see e.g. Blauwet and Willick, 2012; or Andile and Jhalukpreya, 2013). Moreover, the opportunities for the disabled people to engage themselves in various types of sporting activities are becoming increasingly available thanks to the new developments in both sport disciplines and the new technologies (see e.g. Dlodlo and Dhurup, 2013).

The Paralympic Games represents a break-through sporting event that is a part of the broader Paralympic Movement, which provides a base for people with disabilities to compete in front of the broader audience. Moreover, Paralympic Games also bear a very important message being the representative of the disability rights through integration, equality, opportunity, and non-discrimination (Chang and Crossman, 2009).

Worldwide media coverage of the Paralympic Games helped to create the increased awareness of the needs and hopes of people with disabilities and to demonstrate that the human spirit might be stronger than the boundaries that might enchain or restrain it (see Gold and Gold, 2007; Enock and Jacobs, 2008; or Kubayi et al., 2014). In addition, the rising popularity of the Paralympic events helps to sustain the postulate that the power of sport might be useful in stimulating confidence, self-efficiency, reliance, as well as the good quality of life for individuals with disabilities far above the boundaries of day-to-day routine fitness. There is no doubt that the promotion and broad coverage of Paralympic events contributes to the promotion of sports and health in general, as well as helps to enhance the rights of the disabled and their social integration and adaptation. Furthermore, the popularity of Paralympics leads to the expansion of opportunities available for the consecutive generations of athletes with disabilities and therefore draws a path for the other disables individuals to follow in pursuing their dreams.

Our paper focuses on the Czech media and their coverage of the sporting events featuring athletes with disabilities. This comparative and largely qualitative content analysis deals with media coverage of five Summer Paralympics (Barcelona 1992, Atlanta 1996, Sydney 2000, Athens 2004 and Beijing 2008) in three Czech general newspapers ("Mlada fronta Dnes", "Pravo", and "Lidove noviny"), as well as the daily sports newspaper entitled "Sport". 
This paper is organized as follows: Section 2 provides a short literature review on the topic and athletes with disabilities. Section 3 explains the main method of the research and provides the main results of the empirical analysis. Section 4 provides the discussion of obtained results. Section 5 summarizes the main findings and provides overall conclusions.

\section{Media and Athletes with Disabilities}

When it comes to the media coverage of the Paralympics, personal and touching stories of the athletes with disabilities and the optimistic positive image of the Games are the topics that most commonly prevail. Quite often the media tend to focus on presenting specific personal stories or case studies (e.g. the achievements and the hardships of Oscar Pistorius) rather than trying to tackle broader social issues.

Mass media convey a certain representation of reality using the process of stereotyping. Many authors debate that a certain simplification of the world around us is necessary because otherwise we would not be able to orient ourselves in more and more complicated world. This way of simplification is often called categorization (see Pickering, 2001). However, in this context it appears important to differ between categories and stereotypes. Categories are flexible while stereotypes tend to be fixed, although the border between categories and stereotypes can be very narrow. For instance, Shoemaker and Reese (1991) argue that media create stereotypes but some other authors (see e. g. Pickering, 2001; or Haynes, 2007) express an opinion that media do not create stereotypes per se but repeat them to be more persuasive.

Representation plays a dominant role in the construction of identity, the reflection of "us" and "them". It is natural and it starts when human beings are born, on the other hand it can be a germ of prejudices and stereotyping of other people.

According to Bottomley (1992), Pickering (2001) and Hall (2001), "the others" are all people who are different from the majority. Because of being non-disabled, the major society considers a disability as something different, usually in a negative meaning of this word, because a disability can bring about the troubles that might look unsolvable to a person without a disability. On the other hand, people with disabilities are considered to be almost mythical heroes who are able to do things that the normal ("non-disabled") individuals can only imagine of completing.

The "mainstream" society considers the athletes with a disability as something of "the other". It could also be because hardly anyone of the numerous crowds of Czech sport journalists has a disability of any sort, so when any of them is thinking in their mental categories, being "normal" automatically means being non-disabled.

However, it needs to be mentioned that athletes with disabilities also consider themselves to be "the other" (in both meanings of this word). And with defining themselves as such they also try to defend their differentness. The Czech daily "Sport" once quoted a swimmer Martin Kovař after coming back from Athens who proclaimed: "It isn't how majority of people thinks it is - that we come somewhere and some doctor gives us a medal for nothing. Our training is often more difficult and painful than training of athletes without disabilities".

Nowadays, Czech athletes with disabilities can be also considered strangers (Pickering, 2001) in the "mainstream" society. They gained fame and success in the past several years as far as they are overcoming stereotypes about people with disabilities. Clearly, some of the Czech journalists simply do not know where to place these people. The similar situation occurred with Surinam-born football players in the Netherlands (Hermes, 2005). Until they were a small minority in the Dutch national team, they were positively discriminated by the media. Later it was a problem for both media and fans to accept that more than one-third of players were not "white" and "Dutch".

Gardiner (2003) and Darcy (2003) provide an example of Nova Peris-Kneebone and Cathy Freeman who were used by the Australian press in the media coverage of the Summer Olympics in Sydney 2000 for introducing the world of Aborigines and their current situation and for bridging over antipathies between original and "imported" inhabitants. Freeman used this opportunity to ask for an apology of the major society for things it did in the past to her nation and because she was famous her proclamation was heard and widely covered by the Australian media.

The representation of people in media content does not need to be the same as for the "real" population. They could be underrepresented or even overrepresented (see Shoemaker and Reese, 1991; or Haynes, 2007). As Haynes (2007) points out, through representation in the mass media they perceive themselves as the citizens of the world by being globally present and globally relevant. It is the same with people without disabilities who, as our results tend to demonstrate, are also unambiguously underrepresented.

\section{Empirical Analysis: Czech Media and the Coverage of SPG}

Our study set together results of both qualitative and quantitative research that are complementary (Jensen, 2003). The 
main method is a comparative qualitative textual content analysis. It analyses articles from the Czech dailies during the Summer Paralympics covering the news from two weeks prior to the Paralympics and one month after the Games.

While making comparative qualitative analysis we focused mainly on the type of information about sport of people with disabilities that is highlighted by the media. We also analyzed the length and the types of the articles. The method of open-coding described in Lindlof and Taylor (2002) and Tejkalová (2010) was used.

We run a basic quantitative analysis based on Gunter (2003) and Tejkalová (2010). Using the results of this analysis, we were able to map the extent of media coverage and its development over time. We counted the articles and measured their extent. When talking about the extent we have to note here that the daily "Pravo" was a media partner of the Czech Paralympic Committee from 1996 till 2004 and the daily Sport was a partner in 2000 and 2008. Being a media partner implied a somewhat wider coverage of the events in the dailies in question.

In our empirical analysis we employ the comparative content analysis of the articles from the daily newspapers two weeks prior and one month after the respective event using the article total space ranging from $30 \mathrm{~cm}^{2}$ (very short) to 161 $\mathrm{cm}^{2}$ (very long).

\section{Discussion of Main Results}

The aim of this research is not to prove that minor topics have minor media coverage (which is quite clear in this case). It appears more relevant and important to show whether there is some development in the media coverage of the Summer Paralympics, in both the extent and the quality. The main results of the estimations depicting the distribution of articles dedicated to Summer Paralympic Games (1992-2008) in the Czech press by the size and type are presented in Table 1.

Table 1: Distribution of articles dedicated to Summer Paralympic Games (1992-2008) in the Czech press by the size and type

\begin{tabular}{|c|c|c|c|c|c|c|}
\hline \multirow{2}{*}{ Year } & \multicolumn{5}{|c|}{ Article type } & \multirow{2}{*}{ Total } \\
\cline { 2 - 6 } & Very short & Short & Medium & Long & Very long & \\
\hline 1992 & 18 & 15 & 2 & 2 & 3 & 40 \\
\hline 1996 & 7 & 17 & 8 & 5 & 7 & 44 \\
\hline 2000 & 13 & 23 & 8 & 13 & 6 & 63 \\
\hline 2004 & 12 & 25 & 14 & 14 & 11 & 76 \\
\hline 2008 & 14 & 16 & 7 & 5 & 4 & 46 \\
\hline
\end{tabular}

Source: Own estimations

It is apparent from Table 1 that one can observe the regular growth of total numbers of articles and also the numbers of middle length and longer materials from 1992 till 2004 with a decline in 2008 that set the total number back to the statistics of 1996.

Chart 1 shows the trend of the Czech media coverage of the five consecutive Summer Paralympic Games. One can immediately see that after a relative upward trend in the late 1990s and the early 2000s, there came a sharp decline in 2008. The similar situation in proportion of the articles according to their length can be seen in 1992. In total numbers, the situation in 2008 can be best compared to 1996.

Chart 1: Czech media coverage of Paralympic Summer Games in total extent of the articles (in $\mathrm{cm}^{2}$ )

Source: Own estimations

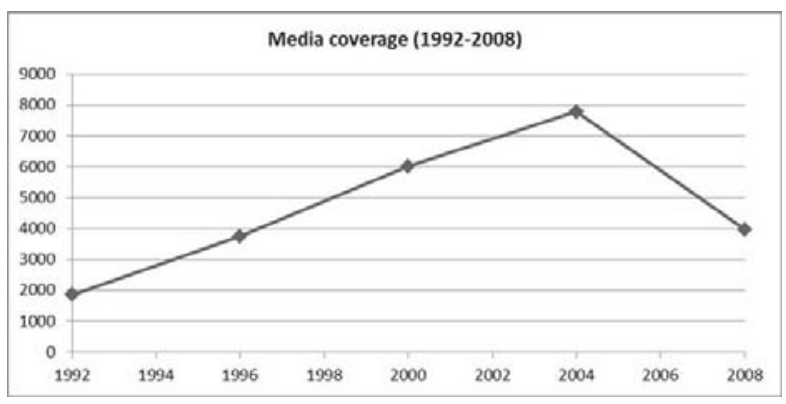


The disproportion between length of articles of the SPG 1996 and 2000 was caused by the type and the kind of articles. During Atlanta Paralympic games, more sports-related features on the Games, e.g. news that that needed more space were published, while during Sydney Paralympics the sport features were rarely covered and there tended to be shorter pieces of news.

It becomes apparent that the trend towards increasing both the space and number of articles is understandable because in the Communist Czechoslovakia, before the Velvet Revolution in 1989, people with disabilities, especially with mental ones, did not have an easy life. After the 1989 attempts were made to revert and to improve this situation.

When interviewed for the other research in 2009 (Němcová Tejkalová, 2014: 365-366), sports section editor-inchief of Mlada fronta DNES said: "First of all, I have to say that I strongly admire those people who, I may say it a bit harshly, don't think about suicide and want to have a place in a society and want to compete in sport. But people will want to have their [Usain] Bolts, someone who is able to show performance on the top level without any physical restriction. So I think that this is the decisive thing." The sports section editor-in-chief of Právo said: "Paralympic sport is not something people would buy newspapers for." This could be reason for the so-called "Beijing change" that describes the ceasing interest of the media (and the general public) in the news coverage of the Paralympics.

However, the other important reason for the "Beijing change" is more complicated. In 2004, almost immediately after coming back from Athens, Czech team leader tried to seize power in the Czech Paralympic Committee (CPC) for improving the situation that he thought was not optimal. He made a few mistakes, which the leaders of CPC used for ignoring both him and the athletes belonging to the organization (called the Czech Sports Organization for Physically Disabled (CSOPD)). This incident triggered off a nasty argument accompanied by the media manipulation on both sides. There was a plethora of articles published about this controversy, which ended by the legal defeat of CSOPD (that was later revoked, but after 2008) and meant troubles for its athletes. Many journalists published the articles full of disappointment and claimed that nearly all things carried out by CPC were foul and that the leaders of CPC were the ones to blame. When it was the same CPC that delegated the Paralympic athletes for the Summer Paralympic Games of 2008, many journalists refused to cover the event, or were very critical about it, which contributed to the decreasing media coverage of the Summer Paralympics in Beijing (and beyond).

\section{Conclusions}

Overall, one can see that the athletes with a disability are clearly underrepresented in the Czech dailies. The media coverage is not relevant to the importance and quality of their achievements. A trend towards the improvement stopped during the Beijing SPG. The people with a disability are a social minority so it is clear that they cannot have the same media coverage as a majority, but according to counting of the Czech Governmental Concept of Social Politics articulated in 2004 , there are about $18 \%$ of people with a disability in the Czech Republic. The extent of media coverage certainly does not create enough coverage for even the one-half of this number of people, not even during such an iconic event as the Summer Paralympic Games.

Since 2008, the Czech media tended to overlook and the Paralympic Games and to swipe their importance and social meaning under the carpet. The justification for that is often that media outlets, having been slammed by the financial crisis, simply lack the funds to cover "minor" sport topics and events that do not yield good profits. This state-ofaffairs culminated in poor Czech coverage of the 2012 Summer Paralympic Games in London. Television, newspapers and online news servers did a very poor job in covering the Games, which led to the fact that, for the first time in history, there was a public outcry and even some politicians expressed their disappointment. As a result, there was a slight improvement of the TV coverage during the Winter Paralympic Games in Sochi in 2014. The coverage consisted mainly of broadcasts of live sledge ice-hockey matches (considering that ice hockey is a very popular sport in the Czech Republic). The last time when some live TV coverage of Paralympic sport was broadcasted in the Czech Republic, was in 2009 during the World Championships in sledge ice-hockey.

We think that it is absolutely crucial for the recognition of sports for athletes with disabilities in the Czech Republic that the public should finally realize that prior to 2012 the topic was underrepresented and that people began to articulate their concern (even if the media only paid attention to politicians' exclamations). Hopefully, public concern will one day lead to massive improvement of the situation and to the increasing interest in Paralympic sports and their broad media coverage.

\section{References}

Andile, M., \& Jhalukpreya, S. (2013). Leadership Behaviour Preferences of Student-Athletes: A Comparative Study of South Africa and 
India. Mediterranean Journal of Social Sciences, 4(11), 81-90

Blauwet, C., \& Willick, S. E. (2012). The Paralympic Movement: using sports to promote health, disability rights, and social integration for athletes with disabilities. $P M \& R, 4(11), 851-856$

Bottomley, G. (1992). Culture, Ethnicity and the Politics/Poetics of Representation. Journal of Sociology (2), 208 - 223.

Chang, I., \& Crossman, J. (2009). When there is a will, there is a way: A quantitative comparison of the newspaper coverage of the 2004 summer Paralympic and Olympic Games. International Journal of Applied Sports Sciences, 21(2), 16-34

Darcy, S. (2003). The politics of disability and access: the Sydney 2000 Games experience. Disability \& Society, 18(6), 737-757

Dlodlo, N., \& Dhurup, M. (2013). Examining Social Media Dimensions among a Cohort of Generation Y Consumers in South Africa. Mediterranean Journal of Social Sciences, 4(14), 329-338

Enock, K. E., \& Jacobs, J. (2008). The Olympic and Paralympic Games 2012: literature review of the logistical planning and operational challenges for public health. Public Health, 122(11), 1229-1238

Gardiner, G. (2003). Running for Country Australian Print Media Representation of Indigenous Athletes in the 27th Olympiad. Journal of sport \& social issues, 27(3), 233-260

Gold, J. R., \& Gold, M. M. (2007). Access for all: the rise of the Paralympic Games. The Journal of the Royal Society for the Promotion of Health, 127(3), 133-141

Hall, S. (2001). The Spectacle of the Other.' In Hall, S. (ed.). Representation. Cultural Representations and Signifying Practices, pp. 224 -279. Thousand Oaks: Sage

Haynes, A. (2007). Mass media re-presentations of the social world: Ethnicity and "race". Media studies: key issues and debates, pp. 162-190. Thousand Oaks: Sage

Hermes, J. (2005). Burnt Orange: Television, Football and the Representation of Ethnicity. Television and New Media, 1, 49-69

Jensen, K. B. (2003). The complementarity of qualitative and quantitative methodologies in media and communication research. In Jensen, K. B. (ed.). A Handbook of Media and Communication Research: Qualitative and Quantitative Methodologies, pp. 254 272. London: Routledge.

Kubayi, N. A., Jooste, J., Toriola, A. L., \& Paul, Y. (2014). Familial and Peer Influences on Sport Participation among Adolescents in Rural South African Secondary Schools. Mediterranean Journal of Social Sciences, 5(20), 1305-1308

Lindlof, T. R. \& Taylor, B. C. (2002). Qualitative Communication Research Methods. Thousand Oaks: Sage.

Němcová Tejkalová, A. (2014). The Role of Power in Articles About Athletes With a Disability. In: Pavličková, T., Reifová, I. (eds.). Media, Power and Empowerment - Central and Eastern European Communication and Media Conference CEECOM Prague 2012, p. 364-369, 1 ${ }^{\text {st }}$ Edition. Newcastle upon Tyne UK: Cambridge Scholars Publishing.

Pickering, M. (2001). Stereotyping: The Politics of Representation. New York: Palgrave Macmillan.

Shoemaker, P. J. \& Reese, S. D. (1991). Mediating the Message - Theories of Influence on Mass Media Content. New York: Longman.

Tejkalová, A. (2010). Sport news and athletes with a disability. In: Pasadeos, Y. (ed.). Advances in communication and mass media research, pp. 113-126, 15t Edition. Athens: Atiner. 